\title{
A systematic review of economic evaluations of therapy in asthma
}

\author{
This article was published in the following Dove Press journal: \\ Journal of Asthma and Allergy \\ 13 August 2010 \\ Number of times this article has been viewed
}

\author{
Katayoun Bahadori' \\ Bradley S Quon ${ }^{2}$ \\ Mary M Doyle-Waters \\ Carlo Marra ${ }^{3}$ \\ J Mark FitzGerald ${ }^{2}$ \\ 'Centre for Clinical Epidemiology \\ and Evaluation (C2E2), ${ }^{2}$ Department \\ of Medicine, Respiratory Division, \\ ${ }^{3}$ Faculty of Pharmaceutical Sciences, \\ UBC, Vancouver, BC, Canada
}

Background: Asthma's cost-effectiveness is a major consideration in the evaluation of its treatment options. Our objective was to perform a systematic review of the cost-effectiveness of asthma medications.

Methods: We performed a systematic search of MEDLINE, EMBASE, CINAHL, Cochrane Database of Systematic Reviews, OHE-HEED, Database of Abstracts of Reviews of Effects, Cochrane Central Register of Controlled Trials, Health Technology Assessments Database, NHS Economic Evaluation Database, and Web of Science and reviewed references from key articles between 1990 and Jan 2008.

Results: A total of 49 RCTs met the inclusion criteria. Maintenance therapy with inhaled corticosteroids was found to be very cost-effective and in uncontrolled asthmatics patients currently being treated with ICS, the combination of an ICS/LABA represents a safe, costeffective treatment. The simplified strategy using budesonide and formoterol for maintenance and reliever therapy was also found to be as cost-effective as salmeterol/fluticasone plus salbutamol. Omalizumab was found to be cost-effective. An important caveat with regard to the published literature is the relatively high proportion of economic evaluations which are funded by the manufacturers of specific drug treatments.

Conclusion: Future studies should be completed independent of industry support and ensure that the comparator arms within studies should include dosages of drugs that are equivalent.

Keywords: asthma, medication, cost-effectiveness, cost of illness, economic costs

Asthma is a chronic disease manifested by variable airflow obstruction and airway inflammation. ${ }^{1}$ There has been a significant increase in the global prevalence, morbidity, mortality, and economic burden associated with asthma over the last 40 years. $^{2}$

The appropriate choice of asthma medication is important in achieving asthma control. There are two major classes of asthma medications - controllers or preventers which reduce inflammation in the airway, and symptom relievers which give symptomatic relief. Inhaled corticosteroids (ICS) are the mainstay of anti-inflammatory therapy and for more severe asthma are usually combined with a long-acting $\beta_{2}$-agonist (LABA). Oral corticosteroids are generally reserved for the treatment of acute asthma exacerbations, although some patients with severe asthma are steroid dependent. Leukotriene modifiers are one of the newer classes of drugs which are available in an oral form and act as anti-inflammatory therapy. Bronchodilators relieve the symptoms of asthma by relaxing airway smooth muscles and are divided into short-acting $\beta_{2}$-agonists (SABA)and LABA.
Correspondence:J Mark FitzGerald Head, UBC and VGH Divisions of Respiratory Medicine, Director, Centre for Lung Health, The Lung Centre, 7th Floor, Gordon and Leslie Diamond Health Care Centre, 2775 Laurel Street, Vancouver, B.C.V5Z IM9, Canada

$\mathrm{Tel}+$ I 6048754122

Fax + I 6048754695

Email markf@interchange.ubc.ca 
Asthma is responsible for significant medical resource utilization and given that it is a chronic condition, costeffectiveness is a major consideration in the evaluation of treatment options. ${ }^{3}$ The costs of asthma medication have increased dramatically since 1985 and this is especially true with the availability of more expensive combination inhalers as well as newer biological drugs such as omalizumab.

To our knowledge, there has been no systematic review evaluating the cost-effectiveness of asthma medications. Our goal in conducting this systematic review is to evaluate the literature with respect to this question.

\section{Method}

\section{Literature review}

A systematic review was conducted to identify English language articles published between 1990 and Jan 2008 that provided data on the cost of asthma medications. The following electronic databases were searched: MEDLINE, EMBASE, Cumulative Index to Nursing and Allied Health Literature (CINAHL), Cochrane Database of Systematic Reviews (CDSR), Health Economic Evaluation Database (OHE-HEED), Database of Abstracts of Reviews of Effects, Cochrane Central Register of Controlled Trials, Health Technology Assessments Database (Technology Assessments), NHS Economic Evaluation Database (Economic Evaluations), and Web of Science and references were reviewed from key articles. Duplicate citations were identified and removed using RefWorks bibliographic management software.

\section{Study selection}

A total of 177 titles and abstracts of all publications identified by the primary literature search were reviewed by two investigators (K.B. and B.Q.), independently. The inclusion and exclusion criteria used for study selection are outlined in Table 1 . The full text of the 80 potentially eligible papers,

Table I Inclusion and exclusion criteria

\begin{tabular}{lc}
\hline Inclusion & Exclusion \\
\hline - English language & - Conference abstracts, case \\
& reports, letters, comments, \\
& editorials, and review papers \\
- Studies that consider the & - Studies that consider asthma \\
costs of asthma medications & with other comorbidities \\
- Studies from 1990 onwards & (such as allergies, COPD) \\
& - Studies that didn't quote \\
& costs in the results section \\
& - Non-RCT trials \\
& - Animal or in vitro studies \\
\hline
\end{tabular}

Abbreviations: COPD, chronic obstructive pulmonary disease; RCT, randomized controlled trials. determined after the first level of screening, were reviewed to assure that each paper met the inclusion criteria for population and outcomes of interest.

For cost data from the United States (US) figures were converted to 2008 US dollars using the medical care component of the consumer price index from the US Bureau of Labor Statistics. For cost data from other countries, costs were first converted to 2008 currency values using the health or equivalent component of that country's consumer price index. Figures were then converted to 2008 US dollars, using currency exchange rates of AUD $\$ 1.00=U S D \$ 0.888$, $\mathrm{CAD} \$ 1.00=\mathrm{USD} \$ 0.998, \mathrm{EUR} \in 1.00=\mathrm{USD} \$ 1.477$, GBP£ $1.00=$ USD $\$ 1.986$. If the year of the cost data was not reported, it was assumed to be the year of article publication. In all cases, both the original cost figures provided in the publications as well as the equivalent costs in 2008 US dollars are reported. Neither intangible costs nor disability adjusted life-years (DALYs) were evaluated in this systematic review.

\section{Data abstraction}

The following information was abstracted from all publications: authors, year of publication, primary country of origin, study design and duration, whether the study was placebo controlled, patient characteristics (population, age, and gender), number of patients enrolled in each treatment arm, types of analysis, cost measurements, and comparative medications.

\section{Methodological quality assessment}

The methodological quality assessment in this review was divided into two parts. First, the quality of the economic evaluations was assessed using the checklist for assessing economic evaluations published by Drummond and Jefferson ${ }^{4}$ (see Table 2). Secondly, the quality of the clinical effectiveness studies was assessed using modified criteria based on CRD Report No. $4 .{ }^{5}$ Study qualities were assessed and data were extracted by one reviewer and confirmed by a second reviewer. Items were scored as positive, negative, or unclear. Randomized controlled trials (RCTs) that fulfilled $50 \%$ or more of the internal validity items were considered of high methodological quality. Any disagreements between the reviewers were resolved through consensus.

\section{Statistical analysis}

Due to the heterogeneity between studies in terms of the variety of medications and unit cost data the results of the 
Table 2 Criteria for evaluating an economic analysis based Drummond and Jefferson assessment method*4

I. Was a well-defined question asked in an answerable form?

2. Was a comprehensive description of the competing alternatives provided?

3. Was there evidence that the program's effectiveness was established?

4. Were all the important and relevant costs and consequences identified?

5. Were costs and consequences measured accurately with appropriate physical units?

6. Were costs and consequences credibly valued?

7. Were costs and consequences adjusted for differential timing?

8. Was an incremental analysis of costs and consequences of alternatives performed?

9. Was a sensitivity analysis performed?

10. Did the presentation and discussion of the study results include all issues of concern to users?

*Note: All items have three possible responses, Yes (+), Cannot tell (N/A), and No (-).

economic evaluations did not allow a quantitative metaanalysis to be completed.

\section{Results}

\section{Literature search}

The primary literature search identified 2,976 citations. After removing duplicate citations there were 2,073 unique citations. Manual screening of all titles and abstracts identified 307 articles that contained primary clinical data evaluating the cost of asthma treatment. Of the 307 full text articles retrieved and reviewed by the investigators, 49 RCT met the inclusion criteria (see Figure 1).

\section{Quality assessment}

Most of the authors of our sample studies clearly described their inclusion and exclusion criteria and the population as well as specifying the primary outcome measures. Eighty-nine percent of studies were rated as being of high-quality. The quality of $65 \%$ of these studies was more than $7 / 10$.

\section{Characteristics of the selected studies}

Of the 49 identified studies, 12 were based in the US, 16 in mainland Europe (mainly Sweden), 10 in the United Kingdom (UK), and two in Canada. Ten of the reviewed studies were multinational. Forty-seven studies involved the evaluation of both the cost and efficacy of the study medication. In each study, comparative effects of different medications on asthma-related health care utilization and costs were reported. Study funding sources according to the articles are reported in Table 3 .
The cost-effectiveness of the different asthma medications evaluated are summarized below:

\section{Inhaled corticosteroids}

The impacts of ICSs on asthma patients as well as their cost-effectiveness were evaluated in 18 studies. ${ }^{6-23}$ In three of the studies it was reported that there was a cost-benefit to the introduction of ICS therapy and that this therapy brought about significant decreases in health care utilization and asthma-related cost. ${ }^{8,11,21}$

\section{Budesonide (with or without other asthma medications)}

In fourteen studies the results of a cost-effectiveness analysis of the ICS budesonide versus placebo or in comparison with other asthma medications were reported. ${ }^{6,9-16,18-22}$ Of these, in five studies it was found that treatment using budesonide, over the long term, was more cost-effective than placebo or other usual asthma therapy, with a substantial reduction in hospitalizations, emergency department visits, and school or caregiver work days missed (see Table 4). ${ }^{9,11,18,21,22}$ It was also shown that the additional drug costs were substantially offset by reduced use of health care services and indirect costs. In a 3-year study evaluating the early use of ICS conducted in eight different countries (Australia, Canada, China, France, Spain, Sweden, UK, and US), treatment with budesonide was also found to be cost-saving in Australia, Canada, and Sweden from both a health care payer and societal perspectives. ${ }^{9}$ Another study randomized patients to receive budesonide with three different doses or placebo. ${ }^{18}$ The investigators found the number of emergency department visits, days lost from work, and days of hospitalization all to be lower in the budesonide groups, leading to significantly reduced total healthcare costs and increased productivity compared to placebo $(P<0.05)$. The average cost in the placebo group was found to be $\$ 37$ per day compared with $\$ 11, \$ 9$, and $\$ 18$ in budesonide $200 \mu \mathrm{g}$, $400 \mu \mathrm{g}$, and $800 \mu \mathrm{g}$ daily dosing groups, respectively. In another high quality study, the cost-effectiveness ratio of budesonide relative to placebo was found to be decreased to $\$ 3.70$ (95\% CI, $\$ 0.10-\$ 8.00) .^{21}$

\section{Comparing the cost-effectiveness ratio of different ICSs}

\section{Fluticasone propionate (FP) versus BUD}

In five studies the cost differences between FP and BUD was explored. Although FP was found to be more expensive than BUD in all studies, when the impact on outcomes was assessed, FP proved to be the most cost-effective 
Total citations identified $(n=2976)$

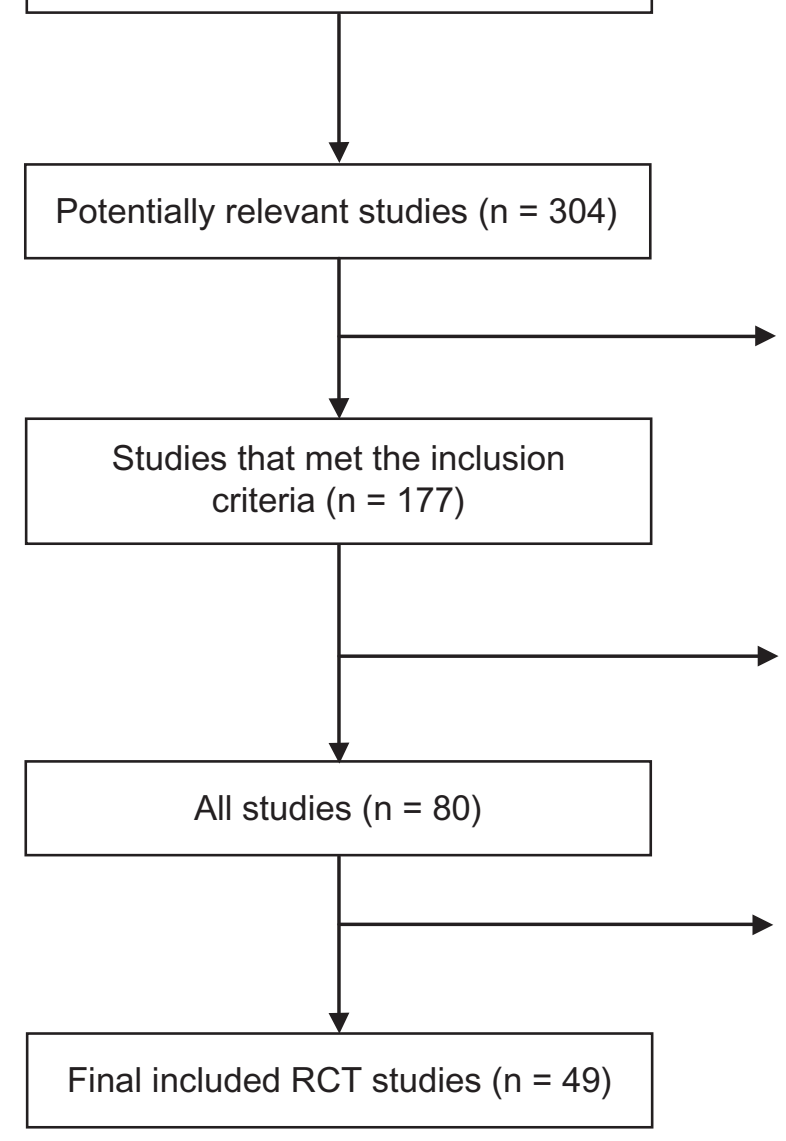

- Asthma with other comorbidities

- Non-English text

- Conference abstracts, case reports, letters, anonymous authors, comments, metaanalyses, editorials, and review papers

- No cost analysis studies

- No economy burden of asthma studies

- No asthma management or asthma intervention studies

Figure I Results of a systematic literature search.

Abbreviations: RCT, randomized controlled trials.

option (Table 5) ${ }^{24-28}$ Delivery of the medications by different devices was found to have no effect on the results in three of the studies. ${ }^{24,26,28}$ In another study, the efficacy and tolerability of FP via a metered-dose inhaler and Volumatic spacer device was compared with nebulized budesonide (nBUD) ${ }^{25}$ Although the study didn't involve an evaluation the cost-effectiveness of the medications, the cost per patient analysis for nebulized budesonide was found to be 1.7 to 3.5 times more expensive than FP. Given the expense of nebulized therapy this result would not be unexpected. In contrast to the above studies, in a clinical trial conducted in UK, it was reported that budesonide, whether administered once or twice daily, was a more costeffective treatment option than fluticasone dry-powder disk inhaler. ${ }^{27}$

\section{FP versus flunisolide (FL)}

In a cost-effectiveness analysis conducted in Germany, in a comparison of two ICS (FP and FL), the average daily treatment in the FP groups was found to be higher than in the FL groups, however, all cost-effectiveness ratios favoured
FP. An incremental cost-effectiveness ratio (ICER) analysis revealed that when switching from FL to FP, there were additional costs of $\$ 5.86$ and $\$ 6.03$ per additional symptomfree day (SFD), and of $\$ 2.82$ and $\$ 2.61$ for each additional successfully treated patient per day, would be incurred. In these patients, management with FP was found to be more cost-effective than with $\mathrm{FL}^{29}$

\section{FP versus triamcinolone acetonide (TA)}

In a further study, FP $250 \mu \mathrm{g}$ twice daily was compared with TA $200 \mu \mathrm{g}$ in patients with persistent asthma. It was found that the daily cost per successfully treated patient based upon a $\geq 12 \%$ increase in forced expiratory volume in one second $\left(\mathrm{FEV}_{1}\right)$ was $\$ 6.15$ for the FP treated group and $\$ 9.60$ for the TA-treated group. In addition, the cost for improvement in symptoms was determined to be $\$ 18.11$ per additional SFD for FP and $\$ 23.40$ per additional SFD for TA. The ICER that would be incurred if patients were switched from the less effective treatment, TA, to FP was $\$ 0.88$ per day for an additional patient to achieve a $12 \%$ improvement in $\mathrm{FEV}_{1} \cdot{ }^{30}$ 
Table 3 Study funding sources according to the articles

\begin{tabular}{|c|c|c|c|}
\hline Reference & $\begin{array}{l}\text { Year of } \\
\text { publication }\end{array}$ & Countrylies & $\begin{array}{l}\text { Sponsoring } \\
\text { companies }\end{array}$ \\
\hline 13 & 2006 & Multicountry & AstraZeneca \\
\hline 16 & 2006 & Sweden & AstraZeneca Sweden \\
\hline 21 & 2003 & US & AstraZeneca Sweden \\
\hline 25 & 1998 & UK & $\begin{array}{l}\text { Glaxo Wellcome, } \\
\text { UK Ltd. }\end{array}$ \\
\hline 26 & 1998 & Germany & Glaxo Wellcome \\
\hline 27 & 1996 & UK & $\begin{array}{l}\text { Astra Pharmaceuticals } \\
\text { Ltd. }\end{array}$ \\
\hline 29 & 1999 & Germany & Glaxo Wellcome \\
\hline 30 & 2000 & US & Glaxo Wellcome, Inc. \\
\hline 31 & 2000 & UK & $\begin{array}{l}\text { AstraZeneca } \\
\text { Pharmaceuticals UK Ltd. }\end{array}$ \\
\hline 32 & 2005 & Multicountry & $\begin{array}{l}\text { AstraZeneca R\&D; } \\
\text { Lund }\end{array}$ \\
\hline 36 & 1998 & Multicountry & Novartis \\
\hline 37 & 1993 & Netherlands & $\begin{array}{l}\text { Netherland's Health } \\
\text { Research Promotion } \\
\text { Program (SGO), Glaxo, } \\
\text { Astra Pharmaceuticals } \\
\text { and Boehringer } \\
\text { Ingelheim }\end{array}$ \\
\hline 41 & 2002 & UK & GlaxoSmithKline Inc. \\
\hline 42 & 2004 & US & GlaxoSmithKline Inc. \\
\hline 43 & 2005 & Multicountry & GlaxoSmithKline Inc. \\
\hline 45 & 2001 & US & GlaxoSmithKline Inc. \\
\hline 47 & 2002 & US & GlaxoSmithKline Inc. \\
\hline 48 & 2007 & Sweden & Novartis Pharma AG \\
\hline 49 & 2006 & Multicountry & Novartis \\
\hline 50 & 1996 & UK & $\begin{array}{l}\text { Glaxo Wellcome } \\
\text { resource }\end{array}$ \\
\hline
\end{tabular}

\section{Long-acting $\beta_{2}$ agonists}

In a further study, patients with mild to moderate asthma were randomized to eformoterol $12 \mu \mathrm{g}$ bid and salmeterol $50 \mu \mathrm{g}$ bid via either a pressurised metered dose inhaler (pMDI) or metered dose powder inhaler (DPI) to determine the cost-effectiveness of each long-acting bronchodilator in the treatment of asthma. Patients had been receiving at least $200 \mu \mathrm{g} /$ day inhaled corticosteroid at a constant dose for at least 4 weeks prior to study entry. Findings in the study indicated that the total medical costs of treating patients with eformoterol were significantly lower than the costs of treating a similar population with salmeterol via either DPI or pMDI ( $\$ 141$ versus $\$ 146$ or $\$ 150$, respectively). The mean cost of achieving a SFD on salmeterol was estimated to be between $25 \%$ (pMDI) and $41 \%$ (DPI) more than achieving the same result using eformoterol Turbuhaler. ${ }^{31}$

\section{LABA versus SABA}

In five studies the use of LABA or SABA medications in the treatment of asthma were compared. ${ }^{32-36}$ Overall, the mean cost-effectiveness ratios of formoterol were found to be higher than those for SABA. The results of three studies indicated that LABA (particularly formoterol) achieved significant improvements in effectiveness, less use of reliever and maintenance medication, and reduced resource utilization, with no increase or only a limited increase in health care cost compared with SABA. ${ }^{32,33,35}$ The first study was based on the Real-Life Effectiveness of Oxis Turbuhaler as needed in asthmatic patients (RELIEF), and evaluated the cost-effectiveness of formoterol $4.5 \mu \mathrm{g}$ and salbutamol $200 \mu \mathrm{g}$ in Sweden and Spain. At study entry, $76 \%$ of patients were being treated with ICS and $31 \%$ with long-acting bronchodilators. Compared to salbutamol, the authors found formoterol to be associated with statistically significant improvements in effectiveness, reduced health care resource utilization, and with lower health care costs in the patients with severe disease. ${ }^{32}$ In a further study, formoterol was compared to terbutaline in combination with inhaled steroids in patients with moderate to severe asthma. In this study lower costs of treatment with for-

Table 4 Studies in which budesonide was found to be more cost-effective than placebo or other usual asthma therapy

\begin{tabular}{|c|c|c|c|c|c|c|}
\hline \multirow[t]{2}{*}{ Ref. \# } & \multirow[t]{2}{*}{ Study duration } & \multirow[t]{2}{*}{ Country } & \multicolumn{2}{|l|}{ Budesonide versus placebo } & \multirow{2}{*}{$\begin{array}{l}\text { Budesonide } \\
\text { Total costs } \\
\text { (patient/yr) }\end{array}$} & \multirow{2}{*}{$\begin{array}{l}\text { Placebo } \\
\text { Total costs } \\
\text { (patient/yr) }\end{array}$} \\
\hline & & & $\begin{array}{l}\text { Health care cost reduction } \\
\text { (patient/yr) }\end{array}$ & $\begin{array}{l}P \\
\text { value } \\
\end{array}$ & & \\
\hline \multirow[t]{3}{*}{9} & 3 yrs & Australia & $\$ 21$ & $<0.05$ & NA & NA \\
\hline & & Sweden & $\$ 48$ & 0.01 & & \\
\hline & & Canada & $\$ 44$ & $<0.1$ & & \\
\hline I I & $6 \mathrm{~m}$ & US & NA & NA & $\$ 3,828$ & $\$ 5,180$ \\
\hline \multirow[t]{3}{*}{18} & $6 \mathrm{~m}$ & US & NA & NA & BT $200 \mu g, n=53, \$ 1 I$ & $\$ 37$ \\
\hline & & & & & BT $400 \mu g, n=55, \$ 9$ & \\
\hline & & & & & BT $800 \mu \mathrm{g}, \mathrm{n}=57, \$ 18$ & \\
\hline \multirow[t]{2}{*}{21} & 3 yrs & US & $\$ 11.30$, Health care perspective & NA & NA & NA \\
\hline & & & $\$ 3.70$, Societal perspective & & & \\
\hline 22 & 3 yrs & US & $192 / 3 \mathrm{yr}$ & NA & NA & NA \\
\hline
\end{tabular}

Notes: All currencies have been converted and inflated to year 2008. $\mathrm{Yr}=$ year(s). 
Table 5 Cost comparison of fluticasone and budesonide

\begin{tabular}{|c|c|c|c|c|c|}
\hline \multirow[t]{2}{*}{ Ref. \# } & \multirow[t]{2}{*}{ Medication and delivery } & \multicolumn{2}{|c|}{ Dose } & \multicolumn{2}{|c|}{ Cost per successfully treated patient } \\
\hline & & $\mathbf{F P}$ & BUD & $\mathbf{F P}$ & BUD \\
\hline \multirow[t]{2}{*}{24} & FP diskhaler versus & 200 & 400 & $\$ 22.77 / w$ & $\$ 24.4 I / w$ \\
\hline & BUD reservoir dry powder device & & & & \\
\hline \multirow[t]{2}{*}{25} & FP via MDI and Volumatic spacer & $\mathrm{l} \mathrm{mg}$ & 2 and $4 \mathrm{mg}$ & $\$ 158.04$ & $\$ 273.75,2 \mathrm{mg}$ \\
\hline & versus BUD nebulizer & & & & $\$ 554.29,4 \mathrm{mg}$ \\
\hline 26 & FP MDI versus BUD Turbuhaler & 250 & 600 & $\$ 3.97 / d$ & $\$ 4.87 / d$ \\
\hline \multirow[t]{2}{*}{27} & FP dry powder disk inhaler device or & 200 & 200 & $\$ 4.12 / d$ & $\$ 2.85 / \mathrm{d}, \mathrm{BUD} 200$ \\
\hline & BUD Turbuhaler & & 400 & & $\$ 2.37 / \mathrm{d}, \mathrm{BUD} 400$ \\
\hline 28 & FP Accuhaler versus. BUD Turbuhaler & 200 & 400 & $\$ 56.84 / w$ & $\$ 93.01 / w$ \\
\hline
\end{tabular}

Note: All currencies have been converted and inflated to year 2008.

Abbreviations: W, week; d, day; N/A, not available; FP, fluticasone propionate; BUD, budesonide; MDI, metered-dose inhaler.

moterol ( $\$ 495$ versus $\$ 542$ per patient, respectively) were demonstrated. ${ }^{33}$ Everden et al found that in children with symptomatic asthma who were receiving SABA and ICS, treatment with eformoterol was significantly more effective and less expensive than treatment with salmeterol $(P=0.034$ and $P<0.001) .{ }^{35}$ In contrast to the above studies, in a high quality multinational trial, the costeffectiveness of formoterol $12 \mathrm{mg}$ metered dose powder inhaler was compared with salmeterol $50 \mathrm{mg}$ inhaled twice daily via Diskhaler in adults with asthma and in which patients were required to keep the dose of ICSs constant throughout the study. In this study no evidence was found to suggest that either treatment was more cost-effective than the other. ${ }^{36}$

\section{ICSs plus LABA}

In eight studies the cost-effectiveness of adding formoterol or salbutamol to BUD in the treatment of moderate, persistent asthma was demonstrated. . $, 8,12-14,16,20,37$ In a cost-effectiveness analysis, a combination of inhaled LABA plus ICS therapy was compared with LABA + placebo (PL) in children with asthma aged 7-16 years. It was found that annual drug acquisition costs for the LABA + ICS were $\$ 478$ higher than for the LABA + PL group. Annual savings due to reduced health care utilization, excluding the cost of study drugs by the group receiving LABA + ICS compared with LABA + PL, were estimated to be about $\$ 272$ per patient. The ICER of LABA + ICS was estimated to be about $\$ 174$ per $10 \%$ increase in $\mathrm{FEV}_{1}$, suggesting the combination of LABA + ICS to be a cost-effective treatment option. ${ }^{37}$

Adding formoterol to budesonide was evaluated in several studies and it was found to be cost-effective in one study, ${ }^{6}$ and less costly in a single inhaler than separate inhalers in two other studies. ${ }^{12,20}$ In another study adjustable maintenance dosing with budesonide/formoterol (one inhalation twice daily, stepping up to four inhalation twice daily for 1 week if asthma worsened) versus fixed dosing (two inhalation twice daily) was compared for 12 weeks in adults with asthma and significantly lower asthma-related direct costs were found in the adjustable maintenance dosing with budesonide/formoterol in a single inhaler (mean: \$339 versus $\$ 448 ; P<0.001){ }^{8}$ In another study patients were randomized to twice-daily treatment with BUD $100 \mu \mathrm{g}$, BUD $100 \mu \mathrm{g}$ plus formoterol $4.5 \mu \mathrm{g}$, BUD $200 \mu \mathrm{g}$, or BUD $200 \mu \mathrm{g}$ plus formoterol $4.5 \mu \mathrm{g}$ for 12 months and the cost-effectiveness of both treatments was compared. ${ }^{14}$ The researchers found that BUD $200 \mu \mathrm{g}$ plus formoterol $4.5 \mu \mathrm{g}$ was more cost-effective than BUD $100 \mu \mathrm{g}$ plus formoterol $4.5 \mu \mathrm{g}$. The ICER for this comparison was found to be $\$ 2.99$ per SFD gained. Results from an economic analysis comparing the strategy of budesonide/formoterol (Symbi$\left.\operatorname{cort}^{\circledR}\right)$ Maintenance and Reliever Therapy (SMART) versus salmeterol/fluticasone (SFC) plus salbutamol demonstrated that the SMART strategy was a cost-effective treatment option from a societal cost perspective, compared with SFC, in Italy, Germany, France, and the UK. The total cost of the SMART strategy was found to be a significantly less costly treatment option than SFC $(\$ 1,416$ versus $\$ 1,590$; $P=0.024) \cdot{ }^{13}$ In another study it was investigated whether the SMART concept could be applied also with only one dose/day as background maintenance therapy. The once daily SMART group $(1 \times$ SMART $)$ was compared with a SMART group using twice the maintenance dose $(2 \times$ SMART). To make the comparison as strong as possible, a third group was treated with a fixed high maintenance dose budesonide/formoterol (FIX), (4-fold higher than the once-daily SMART group), plus formoterol as needed $(2 \times$ 2 FIX + Formoterol). Switching patients from $2 \times 2$ FIX $+F$ treatment regimen to $2 \times$ SMART was found to reduce the cost of drugs by $\$ 13,721 .{ }^{16}$ 


\section{SFC vs ICSs}

In five studies the cost-effectiveness of SFC 50/100 $\mu \mathrm{g}$ with fluticasone propionate $100 \mu \mathrm{g}$ was compared. ${ }^{15,38-41}$ Despite the higher drug costs for SFC, the cost per successfully treated week was found to be lower for SFC than FP alone in all studies. The ICERs reported in three studies were estimated to be $\$ 20.91, \$ 30.12$, and $\$ 26.04$, respectively. ${ }^{38,40,41}$ Similarly, the result of a prospective economic analysis comparing SFC 50/250 mg twice daily versus BUD $800 \mathrm{mg}$ twice daily in adults and adolescents with asthma suggested that SFC was more cost-effective than BUD alone. The costeffectiveness ratio was found to be $\$ 32.69$ and $\$ 48.08$ in the SFC group and the BUD group, respectively. ${ }^{15}$

\section{SFC versus ICS with leukotriene modifiers (LTM)}

In three studies SFC versus ICS plus montelukast were compared, and it was found that SFC had superior clinical benefits and cost-effectiveness compared to the montelukastcontaining regimen..$^{42-44}$ The result of the ICER analyses revealed SFC to be dominant over ICS plus montelukast. ${ }^{42,43}$ Similarly, the results of a combined analysis of four clinical trials, two comparing SFC with montelukast and two comparing FP with montelukast as initial asthma therapy, demonstrated that first line treatment with SFC was associated with a significant lower risk of an asthma-related exacerbation and lower exacerbation-related costs. Mean daily exacerbation costs for patients who experienced an asthma-related exacerbation were \$35 for SFC, \$153 for FP, and $\$ 184$ for montelukast. ${ }^{44}$

\section{Leukotriene receptor antagonist (LTRA) versus ICS}

In one study the differences between LTRA (zafirlukast) versus fluticasone propionate $88 \mu \mathrm{g}$ twice daily and health care resource utilization in asthma patients were examined and the mean daily cost of asthma treatment was found to be $\$ 2.66$ per patient for patients in the FP group and $\$ 4.17$ for those in the zafirlukast group. Using symptom-free days as an effectiveness parameter yielded a mean daily cost-efficacy ratio of $\$ 7.96$ per symptom-free day for the FP group and \$21.63 for the zafirlukast group. Results of the study supported the use of FP as first-line treatment in patients with persistent asthma previously treated with SABA alone. ${ }^{45}$

\section{LTRA vs SFC}

In two studies the relative cost-effectiveness of twice-daily treatment with SFC was determined compared to once-daily treatment with montelukast as an initial maintenance therapy in patients with persistent asthma uncontrolled on shortacting $\beta_{2}$ - agonist therapy alone. In both studies it was found the use of SFC to be more cost-effective than montelukast. The ICER in both studies showed that the additional costs to achieve the benefits with SFC were minimal $-\$ 2.89$ and $\$ 1.62$, respectively. ${ }^{46,47}$

\section{Omalizumab}

In two studies the cost-effectiveness of omalizumab was evaluated. ${ }^{48,49}$ In the first study data from the ETOPA study were gathered and it was suggested that omalizumab was a more cost-effective treatment for patients with inadequately controlled severe persistent allergic asthma; however, their analysis was based on a small open-label trial, and was limited to participants who were responsive to omalizumab. ${ }^{48}$ The INNOVATE study was a multinational study, which estimated the cost-effectiveness of adding omalizumab to optimal standard therapy in patients with severe persistent asthma from a societal perspective. The results showed that omalizumab provided cost offsets of improved quality of life and had an attractive ICER in patients targeted as a selected subgroup of severe patients with allergic asthma who were symptomatic despite best available care and who had an increased risk of needing emergency health care during acute asthma exacerbations. Omalizumab as an add-on therapy was estimated to cost an additional $\$ 57,600$ for 0.76 additional quality adjusted life years (QALYs), resulting in an ICER of $\$ 75,568$. This is a relatively high dollar amount per QALY. ${ }^{49}$

\section{Cromoglycate versus ICSs}

In two studies the cost-effectiveness of ICSs versus sodium cromoglycate in asthma patients was examined. ${ }^{7,50}$ In the first study, the cost-effectiveness of sodium cromoglycate was compared with BUD in children age 5-11 years. It was found that budesonide, when taken for maintenance treatment, after an initial period of stabilizing treatment with BUD, resulted in lower average annual cost $(\$ 1,921$ versus $\$ 2,530$ ) and fewer drug switches than did a strategy with sodium cromoglycate. ${ }^{7}$ In the second study, the cost-effectiveness of FP versus sodium cromoglycate was examined in a group of children with asthma and found that irrespective of the symptomatic or clinical measures of success that were used, there were better outcomes using FP than sodium cromoglycate. The average cost per treatment success for FP was approximately $\$ 50$ compared with $\$ 125$ for sodium cromoglycate. ${ }^{50}$ 


\section{Discussion}

Evaluating the cost-effectiveness of asthma medications is important to ensure the most appropriate choice of asthma medication. It is also particularly relevant due to the increasing burden of illness and the rising costs associated with managing asthma. Assessing differences in health care costs for the treatment of asthma is challenging because of the difficulty in deriving a single representative cost for each drug.

The present systematic review (SR) was aimed at reviewing the literature on the pharmaco-economics of asthma treatment. It adds to the current literature base by providing a systematic review of studies looking at the costs and/or effectiveness of asthma medications. Of the 80 reviewed articles, 49 studies met the inclusion criteria.

Early intervention and long term treatment with antiinflammatory therapy using an ICS was found to be a costeffective treatment option that demonstrated a significant decrease in health care utilization and asthma-specific costs. However, higher doses of ICS were not found to be more cost-effective. Among the ICSs, FP both $100 \mu \mathrm{g}$ /day and $200 \mu \mathrm{g} /$ day proved to be the most cost-effective treatment. For early asthma treatment comparing ICS to a LTRA, ICS was associated with lower asthma-related costs. Similarly, the cromones were found to be a cost-effective medication when compared to placebo but not when compared to ICSs.

Although in several studies in this SR, BDP was reported as being a dominant cost-saving intervention, no published economic evaluations provided any evidence of the superiority of BDP compared to FP. Another systematic review supports the findings in this review regarding BDP as the current cheapest ICS product at doses of 200,400 , and $800 \mu \mathrm{g} /$ day. ${ }^{51}$

In our SR adding inhaled LABA to low to moderate doses of ICS was found to be cost-effective, and adjustable maintenance dosing budesonide and formoterol in a single inhaler was found to maintain significantly lower cost than a fixed dosing strategy. ${ }^{6,8,12-14,17,20}$ These results indicate that when a patient is not adequately controlled on inhaled corticosteroid alone and an additional treatment step is required, switching to a combination of inhaled steroid and LABA combination in a single inhaler can improve asthma control without increasing costs, and may even provide cost savings. Although costs per successfully treated week, episode free day (EFD), and SFD for salmeterol/fluticasone were found to be considerably lower than for other ICSs, LTMs, and ICS plus LTMs; ${ }^{14,38-44}$ the introduction of the SMART strategy was found to be incrementally a further cost-effective management strategy based on improved patient outcomes. ${ }^{13,16}$
In several studies it was demonstrated that the addition of omalizumab to standard therapy reduced the frequency of asthma exacerbations, emergency department visits, and hospitalizations. ${ }^{48,49}$ However, omalizumab is more expensive than any other asthma medication. The incremental costs associated with omalizumab seem considerably high compared with those of other controller medications. Therefore it needs to be targeted to the treatment of patients with poorly controlled asthma despite the use of other therapies.

\section{Conclusion}

Cost-effectiveness analyses provide important data that should be considered when selecting treatment regimens for asthma. The result of this systematic review has demonstrated that maintenance therapy with ICS is very cost-effective. In addition, in patients with asthma uncontrolled on ICS the combination of an ICS/LABA in a single inhaler represents a safe, cost-effective, and convenient treatment. The simplified strategy using budesonide and formoterol for maintenance and reliever therapy was also found to be feasible, safe, and at least as cost-effective as salmeterol/fluticasone plus salbutamol. Omalizumab, although expensive, was found in carefully selected patients to be cost-effective. An important caveat with regard to the published literature in this area is the relatively high proportion of economic evaluations which are funded by the manufacturers of specific drug treatments. Future studies should be completed independent of industry support and also should ensure that the comparator arms within studies include dosages of drugs that are equivalent.

\section{Acknowledgments/disclosure}

JMF is a Michael Smith Foundation for Health Research Distinguished Scholar. This work was supported by the National Sanatorium Association. KB has no conflicts of interest. JMF has received consulting fees and also has spoken at industry organized symposia from companies who market asthma drugs. These companies have included Astra Zeneca, GlaxoSmithKline, Merck Frost, and Nycomed. He is also a member of the Canadian Thoracic Society Asthma Guidelines working group and a member of the Global Initiative in Asthma (GINA) executive and Chair of its Science Committee.

\section{References}

1. McFadden ER. Bronchial asthma. In: Isselbacher KJ, Braunwald E, Wilson JD, Martin JB, Fausi AS, Kasper DL, editors. Harrison's Principles of Internal Medicine. vol. 2. 13th ed. New York, NY: McCraw Hill, 1994; 1167.

2. Braman SS. The global burden of asthma. Chest. 2006;130:4S-12S. 
3. Sullivan S, Elixhauser A, Buist SA, et al. National Asthma Education and Prevention Program working group report on the cost effectiveness of asthma care. Am J Respir Crit Care Med. 1996;154:584-595.

4. Drummond MF, Jefferson TO. Guidelines for authors and peer reviewers of economic submissions to the BMJ. The BMJ Economic Evaluation Working Party. BMJ. 1996;313(7052):275-283.

5. Khan KS, Ter Riet G, Glanville J, et al. Undertaking systematic reviews of research on effectiveness: CRD's guidance for those carrying out or commissioning reviews. York: NHS Centre for Reviews and Dissemination 2001. [Accessed May 15, 2009] Available from: www. york.ac.uk/inst/crd/pdf/crdreport4_complete.pdf

6. Andersson F, Stahl E, Barnes PJ, Moller C, Arheden L. Adding formoterol to budesonide in moderate asthma-health economic results from the FACET study. Respir Med. 2001;95:505-512.

7. Andersson F, Kjellman M, Forsberg G, et al. Comparison of the costeffectiveness of budesonide and sodium cromoglycate in the management of childhood asthma in everyday clinical practice. Ann Allergy Asthma Immunol. 2001;86(5):537-544.

8. Bruggenjurgen B, Selim D, Kardos P, et al. Economic assessment of adjustable maintenance treatment with budesonide/formoterol in a single inhaler versus fixed treatment in asthma. Pharmacoeconomics. 2005;23:723-731.

9. Buxton MJ, Sullivan SD, Andersson LF, et al. Country-specific costeffectiveness of early intervention with budesonide in mild asthma. Eur Respir J. 2004;24(4):568-574.

10. Campbell LM, Simpson RJ, Turbitt ML, Richardson PDI. A comparison of the cost-effectiveness of budesonide $400 \mathrm{mug} /$ day and $800 \mathrm{mug} / \mathrm{day}$ in the management of mild-to-moderate asthma in general practice. $\mathrm{BrJ}$ Med Econ. 1993;6:67-74.

11. Connett GJ, Lenney W, McConchie SM. The cost-effectiveness of budesonide in severe asthmatics aged one to three years. $\mathrm{Br} \mathrm{J} \mathrm{Med}$ Econ. 1993;6:127-134.

12. Ericsson K, Bantje TA, Huber RM, Borg S, Bateman ED. Costeffectiveness analysis of budesonide/formoterol compared with fluticasone in moderate-persistent asthma. Respir Med. 2006;100(4): 586-594.

13. Johansson G, Andreasson EB, Larsson PE, Vogelmeier CF. Costeffectiveness of budesonide/formoterol for maintenance and reliever therapy versus salmeterol/fluticasone plus salbutamol in the treatment of asthma. Pharmacoeconomics. 2006;24(7):695-708.

14. Jonsson B, Berggren F, Svensson K, O’Byrne PM. An economic evaluation of combination treatment with budesonide and formoterol in patients with mild-to-moderate persistent asthma. Respir Med. 2004;98(11):1146-1154

15. Lundback B, Jenkins C, Price MJ, Thwaites RM. Cost-effectiveness of salmeterol/fluticasone propionate combination product 50/250 microg twice daily and budesonide 800 microg twice daily in the treatment of adults and adolescents with asthma. International Study Group. Respir Med. 2000;94(7):724-732.

16. Lundborg M, Wille S, Bjermer L, et al. Maintenance plus reliever budesonide/formoterol compared with a higher maintenance dose of budesonide/formoterol plus formoterol as reliever in asthma: An efficacy and cost-effectiveness study. Curr Med Res Opin. 2006;22(5): 809-821.

17. Malone DC, Luskin AT. Hydrofluoroalkane-134a beclomethasone as a dominant economic asthma therapy. Respir Med. 2003;97(12): 1269-1276.

18. Miyamoto T, Fujino S, Nakajima S, Tollemar U, Liljas B. Cost-effectiveness of budesonide Turbuhaler in the treatment of mildto-moderate asthma in Japan. Allergol Int. 1999;48(4):275-285.

19. O’Byrne P, Cuddy L, Taylor DW, Birch S, Morris J, Syrotuik J. Efficacy and cost -benefit of inhaled corticosteroids in patients considered to have mild asthma in primary care practice. Can Respir J. 1996;3(3): 169-175.

20. Rosenhall L, Borg S, Andersson F, Ericsson K. Budesonide/formoterol in a single inhaler (Symbicort) reduces healthcare costs compared with separate inhalers in the treatment of asthma over 12 months. Int J Clin Pract. 2003;57(8):662-667.
21. Sullivan SD, Buxton M, Andersson LF, et al. Cost-effectiveness analysis of early intervention with budesonide in mild persistent asthma. J Allergy Clin Immunol. 2003;112:1229-1136.

22. Weiss K, Buxton M, Andersson FL, Lamm CJ, Liljas B, Sullivan SD. Cost-effectiveness of early intervention with once-daily budesonide in children with mild persistent asthma: Results from the START study. Pediatr Allergy Immunol. 2006;17:21-27.

23. Bisgaard H, Price MJ, Maden C, Olsen, NA. Cost-effectiveness of fluticasone propionate administered via metered-dose inhaler plus babyhaler spacer in the treatment of asthma in preschool-aged children. Chest. 2001;120(6):1835-1842.

24. Booth PC, Capsey LJ, Langdon CG, Wells NEJ. A comparison of the cost-effectiveness in alternative prophylactic therapies in the treatment of adult asthma. Br J Med Econ. 1995;8:65-72.

25. O'Reilly JF, Weir DC, Banham S, Basran GS, Boyd G, Patel KR. Is high-dose fluticasone propionate via a metered-dose inhaler and Volumatic as efficacious as nebulized budesonide in adult asthmatics? Respir Med. 1998;92(1):111-117.

26. Steinmetz KO, Volmer T, Trautmann M, Kielhorn A. Cost-effectiveness of fluticasone and budesonide in patients with moderate asthma. Clin Drug Investig. 1998;16(2):117-123.

27. Venables TL, McConchie S, Follow R. A comparison of the costeffectiveness of budesonide and Fluticasone dry-powder devices in the management of adult asthma. Br J Med Econ. 1996;10: 315-323.

28. Williams J, Richards KA. Ease of handling and clinical efficacy of fluticasone propionate Accuhaler/Diskus inhaler compared with the Turbohaler inhaler in paediatric patients. UK Study Group. Br J Clin Pract. 1997;51(3):147-153.

29. Volmer T, Kielhorn A, Weber HH, Wiessmann KJ. Costeffectiveness of fluticasone propionate and flunisolide in the treatment of corticosteroid-naive patients with moderate asthma. Pharmacoeconomics. 1999;16:525-531.

30. Stanford RH, Edwards LD, Rickard KA. Cost effectiveness of inhaled fluticasone propionate vs inhaled triamcinolone acetonide in the treatment of persistent asthma. Clin Drug Investig. 2000;20(4): 237-244.

31. Campbell LM, Berggren F, Emmas C. The cost effectiveness of eformoterol via Turbohaler and salmeterol via pressurised metered dose inhaler and metered dose powder inhaler in mild to moderate asthma. J Med Econ. 2000;3:49-60.

32. Lindgren B, Sears MR, Campbell M, et al. Cost-effectiveness of formoterol and salbutamol as asthma reliever medication in Sweden and in Spain. Int J Clin Pract. 2005;59(1):62-68.

33. Berggren F, Ekström T. A cost-effectiveness study comparing the as-needed use of formoterol (Oxis) and terbutaline (Bricanyl) in patients with moderate to severe asthma. Respir Med. 2001;95(9): 753-758.

34. Sculpher MJ, Buxton MJ. The episode-free day as a composite measure of effectiveness: an illustrative economic evaluation of formoterol versus salbutamol in asthma therapy. Pharmacoeconomics. 1993;4(5):345-352.

35. Everden P, Lloyd A, Hutchinson J, Plumb J. Cost-effectiveness of eformoterol Turbohaler versus salmeterol Accuhaler in children with symptomatic asthma. Respir Med. 2002;96(4):250-258.

36. Rutten-van Mölken MP, van Doorslaer EK, Till MD. Cost-effectiveness analysis of formoterol versus salmeterol in patients with asthma. Pharmacoeconomics. 1998;14(6):671-684.

37. Rutten-van Mölken MP, van Doorslaer EK, Jansen MC, van Essen-Zandvliet EE, Rutten FF. Cost-effectiveness of inhaled corticosteroid plus bronchodilator therapy versus bronchodilator monotherapy in children with asthma. Pharmacoeconomics. 1993;4(4):257-270.

38. Johansson G, Price MJ, Sondhi S. Cost-effectiveness analysis of salmeterol/fluticasone propionate 50/100[micro]g vs fluticasone propionate 100 [micro]g in adults and adolescents with asthma III: Results. Pharmacoeconomics. 1999;16:15-21. 
39. Palmqvis M, Price MJ, Sondhi S. Cost-effectiveness analysis of salmeterol/fluticasone propionate 50/250 [micro]g vs fluticasone propionate 250 [micro]g in adults and adolescents with asthma IV: Results. Pharmacoeconomics. 1999;16:23-28.

40. Pieters WR, Lundback B, Sondhi S, Price MJ, Thwaites RMA. Cost-Effectiveness Analysis of Salmeterol/Fluticasone Propionate 50/500[micro]g vs Fluticasone Propionate 500[micro]g in Patients with Corticosteroid-Dependent Asthma V: Results. Pharmacoeconomics. 1999;16:29-34.

41. Price MJ, Briggs AH. Development of an economic model to assess the cost-effectiveness of asthma management strategies Pharmacoeconomics. 2002;20(3):183-194.

42. O'Connor RD, Nelson H, Borker R, et al. Cost-effectiveness of fluticasone propionate plus salmeterol versus fluticasone propionate plus montelukast in the treatment of persistent asthma. Pharmacoeconomics. 2004;22(12):815-825.

43. Pieters WR, Wilson KK, Smith HC, Tamminga JJ, Sondhi S. Salmeterol/ fluticasone propionate versus fluticasone propionate plus montelukast: a cost-effective comparison for asthma. Treat Respir Med. 2005;4(2):129-138,

44. O'Connor RD, Stanford R, Crim C, et al. Effect of fluticasone propionate and salmeterol in a single device, fluticasone propionate, and montelukast on overall asthma control, exacerbations, and costs. Ann Allergy Asthma Immunol. 2004;93(6):581-588.

45. Menendez R, Stanford RH, Edwards L, Kalberg C, Rickard K. Costefficacy analysis of fluticasone propionate versus zafirlukast in patients with persistent asthma. Pharmacoeconomics. 2001;19(8):865-874.
46. Borker R, Emmett A, Jhingran P, Rickard K, Dorinsky P. Determining economic feasibility of fluticasone propionate-salmeterol vs montelukast in the treatment of persistent asthma using a net benefit approach and cost-effectiveness acceptability curves. Ann Allergy Asthma Immunol. 2005;95(2):181-189.

47. Sheth K, Borker R, Emmett A, Rickard K, Dorinsky P. Cost-effectiveness comparison of salmeterol/fluticasone propionate versus montelukast in the treatment of adults with persistent asthma. Pharmacoeconomics. 2002;20(13):909-918.

48. Brown R, Turk F, Dale P, Bousquet J. Cost-effectiveness of omalizumab in patients with severe persistent allergic asthma. Allergy. 2007;62(2):149-153.

49. Dewilde S, Turk F, Tambour M, Sandstrom T. The economic value of anti-IgE in severe persistent, IgE-mediated (allergic) asthma patients: adaptation of Innovate to Sweden. Curr Med Res Opin. 2006;22(9): 1765-1776.

50. Booth PC, Wells NE, Morrison AK. A comparison of the cost effectiveness of alternative prophylactic therapies in childhood asthma. Pharmacoeconomics. 1996;10(3):262-268.

51. Main C, Shepherd J, Anderson R, et al. Systematic review and economic analysis of the comparative effectiveness of different inhaled corticosteroids and their usage with long-acting beta 2 agonists for the treatment of chronic asthma in children under the age of 12 years. Health Technol Assess. 2008;12(20):1-174, iii-iv.

\section{Publish your work in this journal}

The Journal of Asthma and Allergy is an international, peer-reviewed open-access journal publishing original research, reports, editorials and commentaries on the following topics: Asthma; Pulmonary physiology; Asthma related clinical health; Clinical immunology and the immunological basis of disease; Pharmacological interventions and

\section{Dovepress}

new therapies. Issues of patient safety and quality of care will also be considered. The manuscript management system is completely online and includes a very quick and fair peer-review system, which is all easy to use. Visit http://www.dovepress.com/testimonials.php to read real quotes from published authors. 